\title{
QUEEN'S
UNIVERSITY
BELFAST
}

\section{Exploring transition pathways as an alternative approach for the integrated management of Irish estuaries and coasts}

Kelly, C., Ellis, G., \& Flannery, W. (2018). Exploring transition pathways as an alternative approach for the integrated management of Irish estuaries and coasts. In C. P. Heidkamp, \& J. Morrissey (Eds.), Towards Coastal Resilience and Sustainability (pp. 57-78). Routledge.

\section{Published in:}

Towards Coastal Resilience and Sustainability

\section{Document Version:}

Version created as part of publication process; publisher's layout; not normally made publicly available

Queen's University Belfast - Research Portal:

Link to publication record in Queen's University Belfast Research Portal

\section{Publisher rights}

Copyright 2018 Routledge. This work is made available online in accordance with the publisher's policies. Please refer to any applicable terms of use of the publisher.

\section{General rights}

Copyright for the publications made accessible via the Queen's University Belfast Research Portal is retained by the author(s) and / or other copyright owners and it is a condition of accessing these publications that users recognise and abide by the legal requirements associated with these rights.

Take down policy

The Research Portal is Queen's institutional repository that provides access to Queen's research output. Every effort has been made to ensure that content in the Research Portal does not infringe any person's rights, or applicable UK laws. If you discover content in the Research Portal that you believe breaches copyright or violates any law, please contact openaccess@qub.ac.uk. 


\title{
Exploring transition pathways as an alternative approach for the
}

\section{integrated management of Irish estuaries and coasts}

\author{
Christina Kelly, Geraint Ellis and Wesley Flannery
}

\section{Introduction}

Human reliance on estuarine and coastal resources for a multitude of goods and services is under threat. Due to the impact of anthropogenic activities such as agriculture, urban development, commercial fishing and shipping, these resources are being over-exploited, habitats are being destroyed and important species are being lost (EPA, 2016; Rilo et al., 2013). These adverse effects are evident at global, national and local scales, which makes their management, involving multi-levels of governance, challenging. Existing governance frameworks, where management is fragmented among sectors and institutions, are unable to respond to complex and dynamic ecosystems or build capacity to cope with change (Bigagli, 2015; Boyes \& Elliott, 2015; Virapongse et al., 2016). In Ireland, the management of coastal ecosystems is largely carried out in a fragmented, sectoral and uncoordinated manner. There is no overarching national coastal or marine policy and there is no single body with overall responsibility for Irish estuaries and coasts. A more holistic approach is required to deal with the multi-uses, multi-users, multi-scales and multi-effects of estuarine and coastal ecosystems.

The aim of this chapter is to propose an approach for the integrated and sustainable management of estuaries and coasts in Ireland. To do this, it first explores the need for sustainable management, particularly in relation to fragmented governance. Sustainable approaches are analysed and include normative approaches based on the concept of integration. 
Following an evaluation of a normative approach based on an 'ideal' concept of integration within two Irish case studies, it was evident that long-term sustainable management may not be possible without wider systemic change. Sustainability challenges in the coastal zone are interrogated further from the perspective of the emerging field of transitions research and proposed as an alternative way of moving towards sustainable estuaries and coasts, as policy shifts to longer-term perspectives and approaches are deemed critical for environmental sustainability. The chapter concludes by recommending an 'Integration Transition Pathway' based on the key concept of transition management as a more viable means of facilitating integrated management within short-, medium- and long-term governance change.

\section{The need for sustainable management of estuaries and coasts}

Estuaries are used for a wide variety of purposes, which are sometimes in conflict. The conflicting functions and overuse of estuaries and catchments have left many in a degraded state (Millennium Ecosystem Assessment, 2005; European Environment Agency, 2015). Typically, however, the management of coastal ecosystems is undertaken in a largely uncoordinated manner, with governance competencies dispersed across a large number of bodies. In order to halt ongoing degradation and achieve sustainable estuaries, better management of these resources is required.

\subsection{The effects of fragmented governance in estuarine and coastal}

\section{management}

Fragmented arrangements often emerge from deeply embedded conventions and are constrained by previous decisions that create path dependency. According to Kirk et al. (2007, p. 252) "theories of path dependency state that when choices must be made the option most likely to be chosen is that which most closely resembles existing practice or previous choices”. Similarly, 
fragmentation may also materialise from institutional or policy 'layering', which is explained as "gradual institutional transformation through a process in which new elements are attached to existing institutions and so gradually change their status and structure" (van der Heijden, 2011, p. 9). It is imperative, therefore, to recognise that many of the current management or institutional arrangements for estuaries do not necessarily emerge from a grand design, but as a result of ad hoc incrementalism.

\subsection{Shifting paradigm for integrated environmental management}

The legislative and regulatory context relevant to estuary and coastal management is highly complex. As illustrated in Boyes \& Elliott's (2014) 'horrendogram', international conventions and European directives initially compelled a mainly sectoral approach to management. However, this has changed with a more integrated approach being actively promoted through holistic policies such as the Water Framework (WFD), Marine Strategy Framework (MSFD) and Maritime Spatial Planning (MSP) directives.

Adding to this level of legislative complexity, current governance arrangements only exacerbate the fragmented management situation. Boyes \& Elliott's (2015) 'organogram' highlights a multitude of different government departments and agencies with responsibility for estuary and coastal management. In Ireland this is similar, with 34 different agencies sharing responsibility for coastal and marine management. This ad hoc approach results in institutional structures with compartmentalised decision-making processes. This is often denoted by the term 'silo effect', signifying those conditions in which management is fragmented among sectors and institutions with little attention to conflicts or synergies among social, economic and environmental objectives (Holden, 2012; Mitchell, 2005). As a consequence, these arrangements lead to "narrow policy instruments that create incentives for policies and actions that undermine 
sustainability" (Olsson et al., 2008, p. 9489). Therefore new and more effective governance systems are required.

It has been suggested that, in Ireland, the integrated management of estuarine and coastal ecosystems is occurring within a national policy vacuum (O’Hagan \& Ballinger, 2010). This had negative implications for previous attempts at integrated management in Irish coasts. For example, previous management frameworks for Dublin Bay, Bantry Bay and Cork Harbour were never implemented due to a lack of policy commitment, funding and resourcing (Falaleeva et al., 2009; O’Hagan \& Ballinger, 2010; Stevens \& Associates, 2006).

Despite the lack of an overarching coastal or marine policy, there is the potential to learn from international experiences (Kidd, 1995; Lonsdale et al., 2015; Martin, 2014; Morris, 2008; Stojanovic \& Barker, 2008; Elliott, 2013). These experiences can help to conceptualise a move towards the sustainable management of Irish estuaries and coasts.

\subsection{The challenge of 'integration'}

'Integration' is considered a more appropriate response than current piecemeal governance to address the declining health of marine ecosystems and support more sustainable human activities (Elliott, 2013; Holden, 2012; Kidd \& Shaw, 2007; Smith et al., 2011). However, 'integration' is regularly used as a normative concept in environmental management without critical reflection of what this specifically means or how it can be achieved. Consequently, many of the deepseated challenges to the implementation of integrative approaches are overlooked. From a review of the definition and concept of integration and aspects deemed necessary to address the complexities associated with estuarine and coastal management, a number of key observations were noted: 
- The term 'integration' is ambiguous and poorly defined in the literature relating to integrated environmental management.

- Sectoral policy integration is regarded as complex with few examples of best practice (Mullally \& Dunphy, 2015; Stead \& Meijers, 2009; Velázquez Gomar, 2016).

- With regards to 'integration tools' - i.e., approaches, strategies and instruments Runhaar (2016) determined that their performance was usually modest and that expectations should be realistic.

- In relation to territorial (i.e., land-sea) integration, there are many issues in the marine environment that differ from land-use planning - i.e., more focus on natural resources and economic development, and less upon social concerns; in addition, poorly developed understanding of the marine environment, including the scale and significance of land-sea interconnectivities and its 3D nature, is reported by Kidd \& Shaw (2013).

- Organisational/institutional integration must have capacity to address the extensive environmental legislation emanating from the EU which has resulted in an excessively complex administrative and organisational structure for the management of estuaries and coasts.

- The integration of stakeholders in environmental governance tends to be tokenistic to date in coastal and marine management (Flannery et al., 2016).

- The management of estuarine and coastal environments requires an extensive range of knowledge, skills and resources (Borja et al., 2016). 
These observations highlight a number of challenges for integration. However, there are clear benefits to using integrated environmental management as a potential approach towards the sustainable management of estuaries and coasts. As proposed by Cairns (1991, p. 5) integrated environmental management (IEM) is the "co-ordinated control, direction or influence of all human activities in a defined environmental system to achieve and balance the broadest possible range of short-and long-term objectives". Additional benefits of IEM include improved ecosystem status, potential for sustainable multiple use, cost savings and economic competitiveness, effective compliance with legislation and enhanced environmental awareness.

It is acknowledged, therefore, that IEM is an 'ideal type' rarely achieved in practice because of path dependency and institutional inertia.

\section{Methodology}

A critical analysis of the concept of integration and IEM was conducted. Following this appraisal, a suite of sustainability principles of IEM was devised specifically for an Irish context. These principles, along with a review of IEM processes and an analysis of international IEM practical examples, helped to guide the development of an integrated Environmental Management and Monitoring System (EMMS) for Irish estuaries and coasts. The proposed EMMS was based on a normative ideal of IEM and comprised a nine-stage step-by-step process for Irish estuaries and coasts which is described in section 4.

The normative model of EMMS was used as a heuristic device in two Irish case studies to evaluate existing management approaches within these sites, and to explore with stakeholders how the EMMS could be used to achieve integration on a national basis. The two Irish case studies selected were the Shannon Estuary and Dublin Bay, which were in the process of progressing their own innovative estuary and bay management initiatives. These case studies 
represented opportunities to learn about the challenges facing the implementation of the normative model of EMMS. Two one-day workshops were held in each of the case studies and were attended by over 50 stakeholders from a range of organisations including government departments, agencies, local authorities, regulators, research institutes, NGOs, local industries and interest groups. The purpose of presenting the EMMS at the workshops was to instigate a discussion with the stakeholders around existing management initiatives and to consider how the EMMS could be used to achieve sustainability.

Following the workshop events, transcripts were thematically analysed using the software, Atlas TI. The findings revealed that under current management conditions - i.e., without broader institutional change - a normative model of integration was unlikely to achieve the ambition of long-term sustainability in estuaries and coasts. An alternative wider-system approach based on a long-term perspective was deemed necessary. Transition theory presented a more realistic means of conceptualising this change. A proposed 'integration transition pathway' which considers a multi-level and multi-stage transition perspective was explored. This pathway incorporates the relevant stages of the EMMS deemed most effective by the stakeholders and judged to most likely achieve radical, incremental change over short- and medium-term phases. This approach is considered to be a more effective way of thinking about the challenges of sustainable management and provides a means of developing a long-term response to deepseated problems.

\section{Development of a normative EMMS process for Ireland}

A normative model of integration can be derived from:

- Principles of IEM: a set of 15 principles was devised specifically for Ireland and was based on international agreements and environmental protocols. The 
principles were evaluated against a set of criteria based on Elliott's (2013) ten interlinked 'tenets' to achieve successful and sustainable marine management. The principles were revised accordingly and are at the core of the proposed EMMS, which aims to ensure an inclusive, fair, integrated and sustainable management process.

- Integrated processes: a review of integrated processes related to estuarine and coastal management was conducted and included: environmental management; integrated environmental management (IEM); integrated water resource management (IWRM); integrated coastal zone management (ICZM); ecosystembased management (EBM); integrated ecosystem assessment (IEA); and marine spatial planning (MSP). This review clarified that there are a number of common and pertinent stages relevant to progressing the proposed EMMS step-by-step process.

- International practical examples: the practical implementation of these integrated approaches has been analysed within international examples and included examples of ICZM and estuary management plans in England, coastal and marine planning in Scotland, estuary management in the United States and local community-based initiatives in Ireland. This analysis was to further examine and evaluate the effectiveness of such approaches. These examples help to understand real-world contextual conditions pertinent to the implementation of an integrated approach.

Based on the principles of IEM and the review of integrated processes and international examples, a nine-stage step-by-step normative EMMS has been devised and outlined as follows: 
- Stage 1 - Determine vision and objectives

- $\quad$ Stage 2 - Understand ecosystem status

- Stage 3 - Determine ecosystem indicators and reference trends

- Stage 4 - Determine appropriate action

- Stage 5 - Framework planning phase

- Stage 6-Formal adoption

- $\quad$ Stage 7 - Implementation

- Stage 8 - Monitoring and evaluation

- $\quad$ Stage 9 - Adaptation

To test the robustness and rigour of the proposed EMMS, an evaluation exercise was carried out using a set of criteria to check the intended stages and steps for integrated management. The principles of IEM were used once more in this instance, along with a set of essential and desirable criteria derived from the review of integrated processes and international practical examples. The evaluation process suggested that the EMMS was conceptually fit-for-purpose before being used as a heuristic device in the Shannon Estuary and Dublin Bay. While such normative ideas are present in much policy and institutional discourse, the realities of environmental governance mean that they face substantial challenges in implementation.

\section{Identifying and unravelling governance challenges in Irish estuarine}

\section{and coastal management}

As discussed in section 2, there are extensive legislative and regulatory requirements for the management of estuaries and coasts. These represent a magnitude of external pressures from international and European organisations that play an important role in speeding up or slowing down a change in Irish governance. These 'top-down' developments on their own, or 
simultaneously with 'bottom-up' local initiatives, have the potential to exert pressures on the institutions leading to cracks, tensions and windows of opportunity for change (Kuzemko et al., 2016). These dynamic developments can trigger the evolution of a more integrated system of estuary and coastal management and are explored in these two Irish case studies.

\subsection{The Shannon Estuary case study}

The Shannon Estuary is the largest estuary in Ireland, located on the west coast where the River Shannon meets the Atlantic Ocean. The estuary area is a multi-functional zone, with the waters and adjoining lands supporting a range of functions, uses and activities.

The Strategic Integrated Framework Plan (SIFP) for the Shannon Estuary is a recent example of a co-ordinated approach to integrated management in Ireland (Clare County Council et al., 2013). The SIFP, developed by a multi-agency steering group comprising 18 organisations, sets out an integrated marine and land-use planning strategy which facilitates economic growth and promotes environmental management within the Shannon Estuary. The SIFP, however, continues to be implemented in accordance with a plethora of international and national legislation, while the management of the estuary is still the responsibility of numerous governmental departments and agencies. Therefore, despite the external legislative pressures, the current governance system is still resisting change and so local initiatives such as the SIFP strive to exert pressure using a 'bottom-up' approach.

\subsection{Dublin Bay case study}

Dublin Bay is located on the east coast of Ireland, immediately adjacent to the city of Dublin. Dublin Port, the largest in Ireland, is located within Dublin Bay and represents a gateway into the country for millions of visitors each year. 
Currently, there is no person or body with sole responsibility for Dublin Bay and there is no integrated plan for the bay area. This is despite numerous plans having been prepared over the years, including city and county development plans, regional strategies and specifically commissioned studies for the bay and surrounding region (O’Hagan, 2010).

The Eastern and Midland Regional Assembly (EMRA) in association with the Celtic Seas Partnership $^{\mathrm{i}}$ (CSP) recently developed a new strategic management framework (SMF) for Dublin Bay. This has been significant in enhancing stakeholder engagement in the management of the marine resource and has relevance in terms of assisting government in the implementation of the MSFD and MSP in Ireland (EMRA, 2016). The project provided a platform for bringing local, regional and national stakeholders together and found that there was a desire among stakeholders and politically elected representatives to become involved in marine management. The CSP, however, was an EC LIFE+ funded project which finished in December 2016. The follow-up implementation of the SMF for Dublin Bay will be challenging, particularly beyond the lifetime of the project.

The future of the projects in the Shannon Estuary and Dublin Bay is unclear. If there is no political, policy or resource commitment then these initiatives may stall. This type of 'business as usual' approach, or 'status quo' in terms of current management arrangements for estuaries and coasts, may result in a system 'lock-in' as a result of minimal institutional change. To avoid such system outcomes a radical and alternative approach to the current status quo in Irish governance is required. In the two case studies, institutional barriers are examined in more depth as are their potential impacts on future integrated management approaches using the proposed EMMS step-by-step process. These findings will shape how the development of an appropriate 
approach towards the integrated and sustainable management of Irish estuaries and coasts is ultimately achieved.

\subsection{Exploring current and potential management initiatives}

At workshops arranged for each case study, each of the stages of the proposed EMMS was analysed with key stakeholders. The positive aspects of the EMMS process were noted and will be incorporated into the final recommended approach. The opportunities and challenges identified as part of the analysis reflected the possibility of implementing the EMMS process within the current governance arrangements in place in the case study sites. A significant number of constraints were highlighted by the workshop participants which will make the implementation of the EMMS difficult within current institutional structures. These relate to: weak vision, insufficient leadership, uncertainty of resources, lack of policy commitment, inconsistencies between and across government, uncoordinated collection of data and information, inadequate stakeholder engagement, insufficient implementation and communication difficulties. For example, during the stakeholder workshops it was evident that there was an absence of a political or government vision for estuary and coastal management in Ireland. The ongoing delays in finalising and adopting the Foreshore Bill ${ }^{\mathrm{ii}}$ and transposing the MSP directive by means of regulations rather than through primary legislation emphasise the weak vision, lack of leadership and policy commitment of the government in terms of leading the way on integrated marine and coastal management. Some workshop participants also felt that evolving political regimes and short-termism resulted in a lack of commitment and support from politicians for local initiatives. Instead, local initiatives had to compete with other priorities and objectives as well as opposing views and vested interests. Stakeholders highlighted further aggravating issues such as uncertainty over resources, inadequate engagement with citizens and 
lack of trust and communication. These barriers reflect a need for fundamental institutional transformation in the areas of legislation, administration, policies, behaviour, culture and practice. In addition to path dependency and institutional inertia, these combined challenges will limit the EMMS in addressing the long-term sustainable management of estuaries and coasts. It is evident, therefore, that a new paradigm is required to deal with these wider political, economic, ecological and environmental problems based on a longer- term perspective. Before identifying solutions, it is necessary to understand these problems in relation to their causes and this will require breaking down the structures in which they are embedded (Grin, 2010).

The findings from the workshops and stakeholder analysis revealed that there were a number of challenges facing estuary and coastal management which are unable to be addressed through more normative approaches to policy development and incremental institutional reform.

In spite of external or 'top-down' pressures from the EU in terms of directives and 'bottom-up' pressures from local initiatives, there has been resistance from the institutions to radically change or transform current government arrangements in Ireland. This inability to move beyond the existing paradigm is regarded as a 'persistent problem'. Persistent problems have been described as the governance equivalent of Rittel \& Webber's 'wicked problems' which are usually associated with policy-making (Rittel \& Webber, 1973; Verbong \& Loorbach, 2012). Persistent problems cannot be solved by current policies alone; instead they require the application of innovative societal governance approaches (Verbong \& Loorbach, 2012).

These institutional challenges at a national level manifest at a local level. The main issues which emerged from the empirical research of the case studies are all typical of persistent problems, as they exhibit similar characteristics to those identified by Schuitmaker (2012), i.e., 
complex, uncertain, difficult to manage and difficult to grasp. These characteristics of persistent problems in estuarine and coastal management are summarised as follows:

- Complex: estuaries and coasts are socio-economically and ecologically important environments. They are sites of competing and conflicting uses and users. They are associated with fragmented governance arrangements. Previous integrated approaches in Ireland have had mixed success. There are inconsistencies with existing policies across and between levels of government.

- Uncertainty: as previous attempts at integration in Ireland have proven, no successful solution exists in terms of a co-ordinated approach to managing these environments. Lack of vision, political will, diversity, policy commitment, resourcing and insufficient leadership have contributed to uncertainty in the past. Additionally, despite the availability of more information and data, scientific and technical expertise, the reduction of uncertainty by more knowledge has not always been possible. The inconsistent provision of funding has limited innovative local initiatives.

- Difficult to manage: in Ireland, various departments have responsibilities for the management of estuaries and coasts. Many different actors are involved, representing different interests. From the case studies, it was evident that there is a view among stakeholders that some groups have been overlooked during previous attempts at integrated management.

- Difficult to grasp: due to the current fragmented governance and policy vacuum, there is no clear structure in terms of responsibility, leadership, guidance, direction, decision-making, information provision and implementation for 
integrated estuarine management initiatives. From the stakeholder workshops, it is clear that political anchorage is absent. There is a lack of a strong, long-term overriding vision which can guide future reform.

As explored through the Irish case studies, institutional arrangements have a tendency to be constrained by path dependency. This can result in unsustainable practices that become increasingly difficult to change (Schuitmaker, 2012). These institutional norms can have a constraining effect into the future (Greener, 2005) and can occur as a result of institutional inertia. To solve systemic problems, a process of transformation involving both a change in established patterns of action and in the structures in which they take place (system innovation) is needed. An alternative theoretical framework which builds on the positive aspects from the case studies and addresses the key symptoms of persistent problems is explored in the next section.

\section{Transitions - an alternative perspective towards integrated}

\section{sustainability}

Transition studies have emerged in the last two decades as a new field of research which aims to foster societal change towards sustainable development and are broadly concerned with the longterm process of radical and structural change (Grin, 2010; Loorbach \& Rotmans, 2010; Rotmans et al., 2001; van der Brugge et al., 2005). The motivation for sustainable transitions is a radical diagnosis of 'persistent problems'.

A transition perspective recognises the need for a system-wide approach in dealing with persistent problems, which may be required in addition to an IEM managerial approach for estuarine and coastal management in Ireland. Three key elements of transition theory are 
particularly relevant in this context: multi-level perspective (MLP), the multi-stage concept and transition management (van der Brugge et al., 2005).

\subsection{Multi-level perspective (MLP)}

This concept distinguishes between functional scale levels at which transition processes take place. These levels are referred to as niches, regimes and landscapes which have been used to describe technological changes in socio-technical systems (van der Brugge et al., 2005; Grin., 2010).

- Landscape: forms a broad external context determined by changes in the macro economy, politics, population dynamics, natural environment, culture and worldviews. This landscape level represents the wider context within which regimes operate and respond to relatively slow trends, long-term changes and large-scale developments or external shocks that play an important role in speeding up or slowing down a transition (Meadowcroft, 2005; van der Brugge et al., 2005).

- Regimes: are dominant practices, rules and patterns of institutions, assembled and maintained to perform economic and social activities (Meadowcroft, 2005; van der Brugge et al., 2005).

- Niches: are localised areas where innovation can first take place and consists of individual entrepreneurs and innovators willing to take a chance, alternative technologies and local practices. They are the seeds of transition (Geels \& Schot, 2010).

The MLP is a useful analytical concept that helps to explain both how a system of environmental governance in Ireland operates and how it changes. An illustration of the MLP being applied to 
an Irish estuarine and coastal context is outlined in Figure 4.1. At the regime level, the current legislative and regulatory context for estuarine and coastal management in Ireland is reflected in an adaption of Boyes \& Elliott's (2014) ‘horrendogram', while current governance arrangements and structures in Ireland are illustrated in an adaption of Boyes \& Elliott's (2015) 'organogram'.

Figure 4.1 Here

The SIFP and the Dublin Bay SMF are types of innovative niches where partnerships were formed and individual actors are involved at the local level within the two case studies. Developing a management framework was a main aim of both projects, which opened up dialogue between key stakeholders and helped them to rethink current and future goals for each of their ecosystems. The SIFP, at a more advanced stage, has already influenced policy change at the county development plan level. By continuing to exert pressure on the marine policy regime, reinforced by European directives from the landscape level, this transition could continue to influence a system shift towards governance across the land-sea interface. As Olsson et al., (2008) discovered, it is important to identify any political or policy window, as they offer opportunities for large-scale change. For example, the forthcoming Foreshore Bill in Ireland may present an opportunity for policy innovation in relation to estuary and coastal management. Similarly, it is important to create the right links, at an opportune time, around the right issues.

\subsection{Multi-stage concept}

The multi-stage or multi-phase concept (Rotmans et al., 2001) relates to "the systemic change of a dominant regime in four main phases" (Verbong \& Loorbach, 2012, p. 10) which is usually illustrated by an S-shaped pattern. These phases include: 1) pre-development; 2) take-off; 3) acceleration; and 4) stabilisation. It is also accepted that the pathway towards stabilisation represents an 'ideal' transition. In this context, the system "adjusts itself successfully to the 
changing internal and external circumstances, while achieving a higher order of organisation and complexity" (Rotmans \& Loorbach, 2010, p. 127).

In an Irish context, previous unimplemented plans and strategies which had been prepared for coastal areas around Ireland can be conceptualised as never having made it beyond the pre-development stage of the multi-stage concept. There are a number of examples where 'non-ideal' transitions can occur. These manifestations, according to Rotmans \& Loorbach (2010) include the following:

- Increasing path dependence: i.e., choices made in the past exclude different opportunities in the present, e.g., by ingrained behaviour or ideas that get stuck, so that a 'lock-in' situation emerges.

- Choices made early on can also reduce the necessary diversity, causing a niche 'burn-out' or system 'backlash'. This trajectory can be in response to either topdown or landscape pressures or from bottom-up or niche pressures.

- Due to insufficient knowledge, support or embedding in the system, this can lead to so much resistance that the system innovation path will be blocked.

- An overshoot collapse situation may occur. In this case a reverse transition takes place and the system collapses and eventually dies. This could occur due to external shocks and lack of system resilience.

These multi-stages and pathways suggest specific generic examples such as path dependency which could be recognised and understood, particularly in an Irish context.

\subsection{Transition management}

Transition management (TM) was developed as a new governance approach to facilitate and accelerate transitions - i.e., to influence the direction and speed of the change dynamics in 
contributing to end goals such as sustainability or integration. It ultimately co-ordinates multiactor processes at different levels through joint problem-framing, a long-term vision, innovation networks and experimentation, with the aim of achieving long-term sustainability (van der Brugge et al., 2005).

TM is a cyclical and holistic governance framework. The TM cycle comprises different activities coinciding with four stages (Loorbach \& Rotmans, 2010; van der Brugge et al., 2005; Wittmayer et al., 2014) at which policy and negotiation processes take place. Stage 1 focuses on establishing a transition arena and organising a multi-actor network. Within this arena, problem structuring, envisioning and the development of new paradigms and pathways can be developed. Stage 2 involves setting an agenda, coalition-forming and policy deliberation. Stage 3 is the main experimental phase and involves mobilising actors and executing projects and experiments. The fourth and final stage is the reflexive phase which encompasses monitoring, evaluation and learning. These stages will be important considerations in the development of potential pathways towards integrated sustainability at the coast and, in particular, the setting up of a transition arena. A transition arena is an informal and creative space for a group of innovative actors, from various backgrounds, to meet and construct new networks, discourses, agendas and experiments, with the aim of influencing policy and practice. This will be a significant deliberation, particularly when building on the progress of existing partnerships in local management niches.

It is clear that large-scale institutional change over the long term will be necessary to achieve integrated sustainability. Many of the IEM approaches, central to current research in estuarine and marine management (Elliott, 2013; Lonsdale et al., 2015; Sardà et al., 2014) focus only on the intervention, leaving out the context and underlying systemic challenges and problems. The TM approach is more likely to deal with the complexities associated with estuary 
and coastal management which requires a more inter-disciplinary, flexible and adaptive approach.

\section{Proposed 'Integration Transition Pathway'}

Based on the key research outcomes, a potential 'Integration Transition Pathway' has been devised for estuarine and coastal management in Ireland. This approach builds on the findings from the analysis of persistent problems, complexities of estuary management, governance challenges and institutional barriers to change. The pathway represents an amalgamation of the MLP, multi-stage and the TM approach and incorporates the effective IEM instruments within the proposed EMMS. The actions set out within the pathway are ultimately aimed towards system improvement and system innovation over the short, medium and long term. A summary of the recommended stages and actions is included in Table 4.1.

\section{Table 4.1 Here}

The persistent problems associated with system-wide weaknesses in environmental governance and regime impediments have, for many years in Ireland, hindered institutional, legislative, economic and socio-ecological systems change needed for long-term estuary and coastal management. To address these barriers to change, a TM pathway, centred on a shared, long-term, radical vision of sustainability, is recommended. This pathway should build up innovation networks of frontrunners with an ambitious agenda of reform for estuary and coastal management, starting with tangible breakthrough projects, similar to the SIFP for the Shannon Estuary, that illuminate the longer-term sustainability vision (Loorbach \& Rotmans, 2010).

The 'Integration Transition Pathway' therefore recognises individual estuary management initiatives as feeding into a wider transition arena and a network of diverse actors that share the debate, thinking and experimenting. This creates conditions for upscaling and breakthrough of innovations (Loorbach \& Rotmans, 2010). 
The pathway provides guidance for achieving a desirable outcome such as the sustainable management of estuaries and coasts and a desirable direction for the transition as a whole. The suggested stages and actions within the pathway provide a structure to build on the dynamics of the Irish initiatives. It is not a universal blueprint and will have to be adapted to the specific and spatial circumstances and variations emerging throughout the process. As noted by Hansen \& Coenen (2015) sustainability transitions are geographical processes which should be analysed in a regional context having regard to place as a heterogeneous and situated construct (Murphy, 2015), as evidenced from the Irish case studies.

\section{Conclusions}

Estuaries and coasts are highly dynamic and complex ecosystems under significant development pressures which require anticipatory and adaptive management systems that go beyond the existing ways in which policies and strategies are developed (Virapongse et al., 2016). A new kind of governance is needed that develops large-scale institutional change based on a long-term perspective. A process of long-term transformation which incorporates innovative short-term actions based on good practice of integration and environmental sustainability provides a potential solution to this.

As the motivation for sustainable transitions is a radical diagnosis of persistent problems, transition theory presented a more realistic means of conceptualising the long-term change required. Transitions are presented as a new way of realistically progressing towards sustainability. The key concepts discussed in relation to the MLP and the multi-stage pathways have been most effective in contemplating the problems relating to environmental governance and understanding how potential transitions can materialise in estuary and coastal management from innovative niches and external developments. TM is a new governance approach which 
promotes collective choices and learning at different levels through lengthening time horizons, building networks among innovative stakeholders, focusing on sectoral and spatial dynamics and integrating economic, social and environmental considerations in process and policy design. By exploring different options, flexibility is maintained, which is necessary when dealing with great uncertainty and complexity in environmental governance.

An 'Integration Transition Pathway' is proposed based on an amalgamation of the MLP, multi-stage and TM concepts. The actions set out within the pathway are ultimately aimed towards system improvement and system innovation over the short, medium and long term. This approach is considered a more viable means of facilitating sustainable integrated management of estuaries and coasts within long-term governance change. These recommendations align with the overall aims of this edited volume - to address the limitations of transitions research by spatially focusing on two Irish coastal case studies.

It is acknowledged that further research is necessary to advance this conceptual framework in estuarine and coastal management. In particular, future investigation would contribute to a better understanding of barriers to change and therefore help in the design of different pathway options towards sustainability. A particular emphasis would be on establishing transition arenas, championing change agents and encouraging further experimentation, innovation, learning and change. The piloting of coastal case studies and evaluating a range of TM pathways with interested stakeholders would promote further discussion and debate among environmental and marine researchers, policy-makers and decision-makers, with the potential to address unveven development and power imbalances.

A focus on the learning-by-doing and doing-by-learning philosophy can help to guide flexible and adaptive governance strategies that reflect on and draw conclusions from activities 
and lessons learned, making a valuable and practical contribution to this field of research in the future.

\section{Acknowledgements}

This research was funded by the Environmental Protection Agency Ireland (EPA) and

Department of Environment, Community and Local Government (DECLG) through the Science, Technology, Research \& Innovation for the Environment (STRIVE) Research Programme 2007 2013.

Abbreviations

CSP Celtic Seas Partnership

EBM Ecosystem-based management

EMMS Environmental Management and Monitoring System

EMRA Eastern and Midland Regional Assembly

ICZM Integrated coastal zone management

IEA Integrated ecosystem assessment

IEM Integrated environmental management

IWRM Integrated water resource management

MLP Multi-level perspective

MSFD Marine Strategy Framework Directive

MSP Maritime/Marine Spatial Planning

SIFP Strategic Integrated Framework Plan for the Shannon Estuary

SMF Strategic Management Framework for Dublin Bay

TM Transition management

WFD Water Framework Directive 


\section{Bibliography}

Bigagli, E. (2015). The EU legal framework for the management of marine complex socialecological systems. Marine Policy, 54, 44-51. doi:10.1016/j.marpol.2014.11.025

Borja, A., Elliott, M., Snelgrove, P.V.R., Austen, M.C., Berg, T., Cochrane, S., ...Wilson, C. (2016). Bridging the gap between policy and science in assessing the health status of marine ecosystems. Frontiers in Marine Science, 3 (175). doi:10.3389/fmars.2016.00175

Boyes, S. J., \& Elliott, M. (2014). Marine legislation - the ultimate 'horrendogram': international law, European directives and national implementation. Marine Pollution Bulletin, 86(12), 39-47. doi:10.1016/j.marpolbul.2014.06.055

Boyes, S. J., \& Elliott, M. (2015). The excessive complexity of national marine governance systems - has this decreased in England since the introduction of the Marine and Coastal Access Act 2009? Marine Policy, 51(1), 57-65. doi:10.1016/j.marpol.2014.07.019

Cairns Jr., J., \& Crawford, T. V. (Eds.). (1991). Integrated Environmental Management. Michigan: Lewis Publishers.

Clare County Council, Kerry County Council, Limerick City and County Council, and Shannon Development and Shannon Foynes Port Company. (2013). Strategic Integrated Framework Plan for the Shannon Estuary. (Volume 1: Written Statement).

Eastern and Midland Regional Assembly. (2016). Celtic Seas Partnership. Strategic Management Framework for Dublin Bay. Celtic Seas Partnership.

Elliott, M. (2013). The 10-tenets for integrated, successful and sustainable marine management. Marine Pollution Bulletin, 74(1), 1-5. doi:10.1016/j.marpolbul.2013.08.001

EPA. (2016). Ireland's Environment 2016 - An Assessment. Wexford: EPA. 
European Environment Agency. (2015). SOER 2015 - The European Environment - State and Outlook 2015. Synthesis Report. European Environment Agency.

Falaleeva, M., Gray, S., Desmond, M., Gault, J., \& Cummins, V. (2009). The role of ICZM in informing the development of climate adaptation policy in Ireland. Paper presented at the 2009 Amsterdam Conference on the Human Dimensions of Global Environmental Change, Earth System Governance: People, Place and the Planet, Amsterdam, 2-4 December 2009.

Flannery, W., Ellis, G., Ellis, G., Flannery, W., Nursey-Bray, M., van Tatenhove, J.P. M, ...O'Hagan, A.M. (2016) Exploring the winners and losers of marine environmental governance/Marine spatial planning: Cui bono?/ "More than fishy business": epistemology, integration and conflict in marine spatial planning/Marine spatial planning: power and scaping/Surely not all planning is evil?/Marine spatial planning: a Canadian perspective/Maritime spatial planning - “ad utilitatem omnium”/Marine spatial planning: "it is better to be on the train than being hit by it"/Reflections from the perspective of recreational anglers and boats for hire/Maritime spatial planning and marine renewable energy. Planning Theory \& Practice, 17 (1), 121-151. doi:

$10.1080 / 14649357.2015 .1131482$

Geels, F. W., \& Schot, J. (2010). The dynamics of transitions: a socio-technical perspective. In Grin, J., Rotmans, J. \& Schot, J. (Eds.), Transitions to Sustainable Development. New directions in the study of long term transformative change. New York: Routledge, pp. 11. Greener, I. (2005). The potential of path dependence in political studies. Politics, 25(1), 62-72. doi:10.1111/j.1467-9256.2005.00230 
Grin, J. (2010). Understanding transitions from a governance perspective. In: Grin, J., Rotmans, J., \& Schot, J. (Eds.), Transitions to Sustainable Development. New Directions in the Study of Long Term Transformative Change. New York: Routledge, pp. 223.

Hansen, T., \& Coenen, L. (2015). The geography of sustainability transitions: review, synthesis and reflections on an emergent research field. Environmental Innovation and Societal Transitions, 17, 92-109.

Holden, M. (2012). Is integrated planning any more than the sum of its parts?: Considerations for planning sustainable cities. Journal of Planning Education and Research, 32(3), 305318. doi:10.1177/0739456X12449483

Kidd, S. (1995). Planning for estuary resources: the Mersey Estuary Management Plan. Journal of Environmental Planning and Management, 38(3), 435-442. doi:10.1080/09640569512968

Kidd, S., \& Shaw, D. (2007). Integrated water resource management and institutional integration: realising the potential of spatial planning in England. The Geographical Journal, 173(4), (Critical Perspectives on Integrated Water Management), 312-329. doi:10.1111/j.1475-4959.2007.00260

Kidd, S., \& Shaw, D. (2013). Reconceptualising territoriality and spatial planning: insights from the sea. Planning Theory and Practice, 14(2), 180-197. doi:10.1080/14649357.2013.784348

Kirk, E., Reeves, A., \& Blackstock, K. (2007). Path dependency and the implementation of environmental regulation. Environment and Planning C Government and Policy, 25 (2), 250-268. doi:10.1068/c0512j 
Kuzemko, C., Lockwood, M., Mitchell, C., \& Hoggett, R. (2016). Governing for sustainable energy system change: politics, contexts and contingency. Energy Research and Social Science, 12, 96-105. doi:10.1016/j.erss.2015.12.022

Lonsdale, J., Weston, K., Barnard, S., Boyes, S. J., \& Elliott, M. (2015). Integrating management tools and concepts to develop an estuarine planning support system: a case study of the Humber Estuary, Eastern England. Marine Pollution Bulletin, 100 (1), 393-405. doi:10.1016/j.marpolbul.2015.08.017

Loorbach, D., \& Rotmans, J. (2010). The practice of transition management: examples and lessons from four distinct cases. Futures, 42(3), 237-246. doi:10.1016/j.futures.2009.11.009

Martin, L. (2014). The use of ecosystem services information by the US national estuary programs. Ecosystem Services, 9(0), 139-154. doi:10.1016/j.ecoser.2014.05.004

Meadowcroft, J. (2005). Environmental political economy, technological transitions and the state. New Political Economy, 10(4), 479-498. doi:10.1080/13563460500344419

Millennium Ecosystem Assessment. (2005). Ecosystems and Human Well-being: Wetlands and Water Synthesis. Washington, DC: World Resources Institute.

Mitchell, B. (2005). Integrated water resource management, institutional arrangements, and landuse planning. Environment and Planning A, 37(8), 1335-1352. doi:10.1068/a37224

Morris, R.K.A. (2008). English Nature's Estuaries Initiative: a review of its contribution to ICZM. Ocean and Coastal Management, 51(1), 25-42. doi:10.1016/j.ocecoaman.2007.05.001

Mullally, G. \& Dunphy, N. (2015). State of Play Review of Environmental Policy Integration Literature. Report for the National Economic and Social Council (NESC). (Research 
Series No. Paper No.7). NESC. Retrieved 8 July 2015, from:

http://www.nesc.ie/en/publications/publications/nesc-research-series/envpolicyintegration/

Murphy, J.T. (2015). Human geography and socio-technical transition studies: promising intersections. Environmental Innovation and Societal Transitions, 17, 73-91. doi:10.1016/j.eist.2015.03.002

O’Hagan, A. M. (2010). New structures for Integrated Coastal Management and Monitoring around Dublin Bay. Retrieved 15 January 2016, from: http://ec.europa.eu/ourcoast/index.cfm?menuID=6andarticleID $=291$

O’Hagan, A.M., \& Ballinger, R.C. (2010). Implementing Integrated Coastal Zone Management in a national policy vacuum: local case studies from Ireland. Ocean and Coastal Management, 53(12), 750-759. doi:10.1016/j.ocecoaman.2010.10.014

Olsson, P., Folke, C., \& Hughes, T.P. (2008). Navigating the transition to ecosystem-based management of the Great Barrier Reef, Australia. Proceedings of the National Academy of Sciences of the United States of America, 105 (28), 9489-9494. doi:10.1073/pnas.0706905105

Rilo, A., Freire, P., Guerreiro, M., Fortunato, A.B., \& Taborda, R. (2013). Estuarine margins vulnerability to floods for different sea level rise and human occupation scenarios. Journal of Coastal Research, 65, 820-825. doi:10.2112/SI65-139

Rittel, H.W.J., \& Webber, M.M. (1973). Dilemmas in a general theory of planning. Policy Sciences, 4(2), 155-169. doi:10.1007/BF01405730

Roorda, C., Wittmayer, J., Henneman, P., van Steenbergen, F., Frantzeskaki, N., \& Loorbach, D. (2014). Transition Management in the Urban Context. Guidance Manual. Rotterdam: 
DRIFT. Retrieved 20 October 2016, from https://drift.eur.nl/publications/transitionmanagement-urban-context-guidance-manual/

Rotmans, J., \& Loorbach, D. (2010). Towards a better understanding of transitions and their governance. A systemic and reflexive approach. In: Grin, J., Rotmans, J., \& Schot, J. (Eds.), Transitions to Sustainable Development. New Directions in the Study of Long Term Transformative Change. London: Routledge, pp. 105.

Rotmans, J., Kemp, R., \& van Asselt, M. (2001). More evolution than revolution: transition management in public policy. Foresight, 3(1), 15-31. doi:10.1108/14636680110803003

Runhaar, H. (2016). Tools for integrating environmental objectives into policy and practice: what works where? Environmental Impact Assessment Review, 59, 1-9. doi:10.1016/j.eiar.2016.03.003

Sardà, R., O’Higgins, T., Cormier, R., Diedrich, A., \& Tintoré, J. (2014). A proposed ecosystembased management system for marine waters: linking the theory of environmental policy to the practice of environmental management. Ecology and Society, 19(4). doi:/10.5751/ES-07055-190451

Schuitmaker, T. J. (2012). Identifying and unravelling persistent problems. Technological Forecasting and Social Change, 79(6), 1021-1031. doi:10.1016/j.techfore.2011.11.008

Smith, H., Maes, F., Stojanovic, T., \& Ballinger, R. (2011). The integration of land and marine spatial planning. Journal of Coastal Conservation, 15(2), 291-303. doi:10.1007/s11852010-0098-z

Stead, D., \& Meijers, E. (2009). Spatial planning and policy integration: concepts, facilitators and inhibitors. Planning Theory and Practice, 10(3), 317-332. 
Stevens \& Associates. (2006). Scottish Natural Heritage. A review of relevant experience in sustainable tourism in the coastal and marine environment. Case Studies - Level 1. The Bantry Bay Charter. Retrieved 7 July 2016, from www.snh.org.uk/pdfs/strategy/natparks/CMNP/advice/Final\%20report\%20\%20CMNP\%20sustainable\%20tourism\%20-\%20February\%202006.pdf

Stojanovic, T., \& Barker, N. (2008). Improving governance through local coastal partnerships in the UK. Geographical Journal, 174(4), 344-360. doi:10.1111/j.1475-4959.2008.00303.

Van der Brugge, R., Rotmans, J., \& Loorbach, D. (2005). The transition in Dutch water management. Regional Environmental Change, 5(4), 164-176. doi:10.1007/s10113-0040086-7

Van der Heijden, J. (2011). Institutional layering: a review of the use of the concept: institutional layering. Politics, 31(1), 9-18. doi:10.1111/j.1467-9256.2010.01397.

Velázquez Gomar, J. (2016). Environmental policy integration among multilateral environmental agreements: the case of biodiversity. International Environmental Agreements: Politics, Law and Economics, 16(4), 525-541. doi: 10.1007/s10784-014-9263-4

Verbong, G., \& Loorbach, D. (2012). Governing the Energy Transition: Reality, Illusion or Necessity? New York: Routledge.

Virapongse, A., Brooks, S., Metcalf, E.C., Zedalis, M., Gosz, J., Kliskey, A., \& Alessa, L. (2016). A social-ecological systems approach for environmental management. Journal of Environmental Management, 178, 83-91. doi: 10.1016/j.jenvman.2016.02.028

Wittmayer, J., Roorda, C., \& van Steenbergen, F. (2014). Governing urban sustainability transitions - inspiring examples. DRIFT. Retrieved 7 June 2016, from 


\section{https://drift.eur.nl/publications/governing-urban-sustainability-transitions-inspiring-}

\section{examples/}

Figure 4.1 An example of the multi-level concept of transitions being applied to an Irish

\section{estuarine and coastal context}

Table 4.1 Summary of the recommended stages and actions included in the 'Integration Transition Pathway' for estuary and coastal management in Ireland

\begin{tabular}{|c|c|c|}
\hline \multicolumn{3}{|c|}{ Short term (0-3 years) } \\
\hline Multi-stage & Recommended steps & Key actions \\
\hline $\begin{array}{l}\text { 1. Establishing a } \\
\text { transition arena }\end{array}$ & $\begin{array}{ll}\text { - } & \text { Forming a transition } \\
\text { - } & \text { Setting the scene } \\
\text { - } & \text { System and actor } \\
& \text { analysis } \\
\text { - } & \text { Selection of } \\
\text { frontrunners } \\
\text { - } & \text { Establish transition } \\
\text { - } & \text { Prena } \\
\text { - } & \text { Frableming challenges }\end{array}$ & $\begin{array}{l}\text { - } \quad \text { An initiating agency forms transition } \\
\text { - } \quad \text { Speam } \\
\text { - } \quad \text { Agree on short-term goals } \\
\text { - } \quad \text { Draft a process plan and explore } \\
\text { appropriate resources } \\
\text { - } \text { - } \text { space, timeate the system boundaries in } \\
\text { relevant stocks covering the social, } \\
\text { environmental and economic } \\
\text { domains } \\
\text { - } \quad \text { Idellect and analyse data } \\
\text { agents through desktop research, } \\
\text { interviews and participative } \\
\text { workshops } \\
\text { Selection of frontrunners for } \\
\text { transition arena } \\
\text { Arrange regular meetings to share } \\
\text { information, explore challenges and } \\
\text { frame problems }\end{array}$ \\
\hline 2. Envisioning & $\begin{array}{ll}\text { - } & \text { Sharing a vision } \\
\text { - } & \text { Agenda building } \\
\text { - } & \text { Transition pathways } \\
\text { - } & \text { Transition agenda }\end{array}$ & $\begin{array}{l}\text { - } \quad \text { Exchanging perspectives on the future } \\
\text { - } \quad \text { principles } \\
\text { - } \quad \text { Creating visionary images } \\
\text { - } \quad \text { Elaborating the vision } \\
\text { - } \quad \text { Backcasting } \\
\text { - } \quad \text { Identifying short-term actions } \\
\text { - } \quad \text { Consolidating the transition agenda }\end{array}$ \\
\hline \multicolumn{3}{|c|}{ Medium term (3-10 years) } \\
\hline $\begin{array}{l}\text { 3. Steering } \\
\text { process and } \\
\text { experimentation }\end{array}$ & $\begin{array}{l}\text { Engaging and } \\
\text { anchoring } \\
\text { Transition } \\
\text { experiments } \\
\text { Examples: Record and } \\
\text { map uses; Scope } \\
\text { pressures and } \\
\end{array}$ & $\begin{array}{l}\text { Kickstart the process with an event } \\
\text { - } \quad \text { Undertake activities to support } \\
\text { initiatives } \\
\text { - } \quad \text { Setting up initiatives: specific actions } \\
\text { of the transition agenda are selected } \\
\text { and progressed } \\
\text { - } \quad \text { Establish working groups where }\end{array}$ \\
\hline
\end{tabular}




\begin{tabular}{|c|c|c|}
\hline & $\begin{array}{l}\text { impacts; Examine } \\
\text { interconnections; } \\
\text { - } \quad \text { Develop indicators and } \\
\text { determine trends; } \\
\text { - } \quad \text { Consider risk and } \\
\text { decision analysis } \\
\text { Radical short-medium term } \\
\text { actions } \\
\text { - } \quad \text { Developing an } \\
\text { Estuary/ coastal } \\
\text { planning support } \\
\text { system } \\
\text { - Consultation } \\
\text { - Management } \\
\text { strategies } \\
\text { Assist plan-making } \\
\text { process } \\
\text { Pilot changes to } \\
\text { influence legislative } \\
\text { and governance } \\
\text { change }\end{array}$ & $\begin{array}{l}\text { required to work on initiatives } \\
\text { - Supporting initiatives: a co-ordinating } \\
\text { team can assist or facilitate the work } \\
\text { of the working groups and other } \\
\text { sustainability initiatives by mapping } \\
\text { relevant actors, creating a network, } \\
\text { searching for funds and playing an } \\
\text { active role in the project themselves. }\end{array}$ \\
\hline \multicolumn{3}{|c|}{ Longer term (10-25yrs) } \\
\hline $\begin{array}{l}\text { 4. Monitoring, } \\
\text { evaluation and } \\
\text { reflexivity }\end{array}$ & $\begin{array}{ll}- & \text { Implementation } \\
\text { - } & \text { Learning } \\
\text { - } & \text { Reflexive governance } \\
& \text { Visioning of system } \\
\text { - } & \text { Lansition } \\
& \text { institutional change }\end{array}$ & $\begin{array}{ll}\text { - } & \text { Examine achievements } \\
\text { - } & \text { Monitor and evaluate transition } \\
\text { - } & \text { Refocesses and actors } \\
\text { - } & \text { Radical suggestions for large-scale } \\
\text { institutional change } \\
\text { - } \\
\text { Major shifts in dominant structures, } \\
\text { cultures and practices } \\
\text { Achieve vision of environmental } \\
\text { governance and sustainability }\end{array}$ \\
\hline
\end{tabular}

Source: adapted from Roorda et al. (2014)

${ }^{\mathrm{i}}$ Celtic Seas Partnership was a funded EC LIFE+ project (more information at:

\section{www.celticseaspartnership.eu/about-us/)}

ii The Irish Government is currently proposing legislative changes under the General Scheme of Maritime Area and Foreshore (Amendment) Bill 2013. The changes have yet to be finalised. 